\title{
Formação complexa e transdiciplinar na educação: um desafio alem da fragmentação
}

\author{
Magda Pereira Pinto, Icesp Promove-Núcleo Interdisciplinar de \\ Pesquisa NIP, Apoio: Fundação de Apoio à Pesquisa FAPDF, Distrito \\ Federal, Brazil
}

\begin{abstract}
Resumen: $O$ artigo visa descrever a importância da complexidade e transdisciplinaridade como forma de suprir o modelo disciplinar e fragmentador da educação. Podemos observar que a história do conhecimento tem grande influência da lógica fragmentadora. Essa constatação nos remete ao método cartesiano, baconiano, onde para se entender o mundo deveria dividi-lo, fragmentá-lo para que possa ser melhor compreendido. Esse paradigma foi exaltado e teve seu valor num dado momento histórico e exerce até os dias de hoje imprescindiveis influências na nossa educação. Contudo, no periodo contemporâneo temos tido diversas reflexões a respeito do paradigma disciplinar, onde tudo é realizado de forma especializada e segmentada. Temos visto surgir diversas propostas revendo e analisando os fundamentos desse modelo e propondo outros que possam complementá-lo ou mesmo superá-lo. Nesse sentido, pretendemos apresentar a importância do paradigma complexo e transdisciplinar que têm apoiado algumas instituições de ensino no Brasil. Pretendemos assim, através desse artigo, descrever os aspectos epistemológicos e metodológicos desse debate, bem como apresentar o resultado de quatro instituições que desenvolvem suas atividades a partir dessas abordagens.
\end{abstract}

Palabras Clave: Educação, Complexidade, Transdisciplinaridade, Disciplinaridade, Novos Paradigmas.

Abstract: This article aims to describe the importance of complexity and transdisciplinarity as a way to supplement the disciplinary and fragmenting model of education. We can observe that the history of knowledge has great influence of this fragmenting logic. This observation leads us to the Cartesian method, Baconian, where in order to understand the world we might break it up, fragment it so it can be better understood. This paradigm was elated and had its value in a given historical moment and still has essential influences in our education. However, in the contemporary period we have had several discussions about the disciplinary paradigm, where everything is done in a specialized and segmented way. We have seen several proposals reviewing and analyzing the basics of this model and proposing others that can complement it or even overcome it. In this sense, we intend to present the importance of complex and transdisciplinary paradigm that have supported some educational institutions in Brazil. We thus intend, through this article, describe the epistemological and methodological aspects of this debate, and present the result of four institutions that develops its activities based on these approaches.

Keywords: Education, Complexity, Transdisciplinarity, Disciplinarity, New Paradigms

Revista Internacional de Educación y Aprendizaje

Volumen 1, 2013, http://sobrelaeducacion.com/revistas/coleccion/, ISSN 2255-453X

(C) Global Knowledge Academics. Magda Pereira Pinto

Todos los Derechos Reservados. Permisos: soporte@gkacademics.com 


\section{Introducción}

$\mathrm{V}$

ISÃO FRAGMENTADA QUE o modelo cartesiano inspirou, provocou inevitavelmente o debate inter, multi e transdisciplinar, pois antes analisávamos a questão educacional privilegiando apenas alguns aspectos de forma compartimentada. Contemporaneamente, essa análise é expandida, sendo o grande desafio a integração de diversas áreas como a ecologia, a biologia, a antropologia, a filosofia e a pedagogia, entre outras, numa possibilidade de diálogo em torno das complexas relações dos Seres com os fenômenos da vida. Nesse sentido, a discussão em torno da complexa relação humana e os parâmetros de aprendizagem e uma possível reflexão a respeito dos valores que permeiam essa relação vêm ganhando força ao longo da nossa trajetória histórica.

Entre outros paradigmas que surgiram no período contemporâneo o modelo complexo e transdisciplinar tem tido destaque em alguns eventos acadêmicos, surgindo como perspectiva preponderante no que se refere à crítica ao positivismo, à visão linear e fragmentadora. É um paradigma que busca sobretudo refletir sobre a importância da visão complexa mais ampla e não segmentadora. Temos visto surgir diversas propostas que possam rever e analisar os fundamentos desse modelo positivista e propor outros que possam superá-lo ou mesmo complementá-lo.

Nesse sentido, pretendemos apresentar a importância do paradigma complexo e transdisciplinar que têm apoiado algumas instituições de ensino no Brasil. Pretendemos assim, através desse artigo, descrever os aspectos epistemológicos e metodológicos em torno desse debate e também apontamos os resultados de pesquisa de quatro instituições, apontando alguns indicadores em torno da temática abordada.

\section{Refletindo sobre o positivismo e os outros paradigmas}

A questão do conhecimento é em si uma grande polêmica, uma vasta reflexão não só epistemológica, mas também de cunho ontológico e metodológico. Baseamos, há muito tempo, nossa forma de conhecer na perspectiva disciplinar, segundo a qual a vertente positivista serve de estrutura para essa proposta; podemos, assim, verificar uma forma de conhecer os fenômenos numa visão no mínimo especializada.

Podemos verificar que o positivismo mecaniza o sujeito, elimina suas dimensões afetiva e emocional, seus desejos, ou seja, sua perspectiva qualitativa. O sujeito é ignorado em suas próprias ações, ele é submetido a uma esfera de abstração dentro do processo de construção do conhecimento, não só no aspecto emocional que o compõe, mas também nas possíveis influências imprevisíveis que mantém com o seu meio.

Morin (1998, p.103) destaca que a inteligência, compartimentada, mecânica, reducionista, quebra o complexo do mundo, produzindo fragmentos da realidade; fraciona os problemas, separando o que está ligado, é uma forma de unidimensionar o que é multidimensional:

A redução e a simplificação foram métodos heurísticos. Assim, por exemplo, foi preciso simplificar, ou seja, por entre parênteses o problema do sujeito para ver apenas o objeto; foi preciso isolar o objeto estudado tanto do sujeito que o concebe quanto do seu ambiente.

Ele destaca, ainda, que esse método reducionista, simplificador, conduziu a progressos fabulosos tais como as descobertas de Newton e Einstein. 
Como percebemos, existe uma imensa reflexão sobre os pressupostos da razão que nos tem impulsionado em nossa trajetória civilizacional. Por muito tempo, somos guiados por uma ética baseada na razão positivista, instrumental, razão que ainda influencia nossa conduta diante da realidade. Contudo, essa ética, a reflexão sobre nossos valores e conduta diante da vida está em constante mutação; desse modo, a perspectiva epistemológica que adotamos tem uma forte influência em nossas atitudes e reflexões, pois não só aponta a forma como compreendemos, mas também como explicamos o que conhecemos, o que sabemos, enfim, como se constrói um determinado conhecimento da realidade.

Diante desse contexto, Morin (2008) e Capra (1996), entre outros autores, reconhecem a limitação dessa perspectiva e apontam o problema do conhecimento como um desafio que só poderá ser enfrentado numa perspectiva mais ampla, mais complexa. Capra reforça ao dizer que o conhecimento só pode ser verdadeiramente verificado se houver uma interação entre as partes e o todo: "só podemos conhecer as partes se conhecermos o todo em que se situam, e só podemos conhecer o todo se conhecermos as partes que o compõem."

Essa perspectiva em favor de um paradigma diferenciado é citada por Santos (2006, p.141) ao descrever que as novas ciências a partir do século XX buscam a complexidade inerente da realidade, são acima de tudo antirreducionistas:

Em vez do simples, o complexo; em vez da reversibilidade, a irreversibilidade; em vez do tempo linear, os tempos não lineares; em vez da continuidade, a descontinuidade; em vez da realidade construída ou criada, os processos de criação e as qualidades emergentes; em vez da ordem, a desordem; em vez da certeza, a incerteza; em vez do equilíbrio, a instabilidade e ramificações; em vez do determinismo e dos sistemas lineares, o caos e o caos determinista e a teoria das catástrofes; em vez da prioridade da investigação da relação causa-efeito, a prioridade da investigação dos meios para atingir os objectivos; em vez da separação entre sujeito e objecto, o objecto que é sujeito; em vez da separação entre observador e observado, o observador na observação; em vez da separação entre o pensar e o agir, a interactividade entre ambos no processo de investigação.

Para o autor, essas perspectivas visam, sobretudo, uma enorme variedade interna, uma redefinição de conduta e percepção diante da realidade. A proposta do antirreducionismo e do antideterminismo é a aspiração de uma unidade científica, da aceitação da complexidade tão negada pela ciência clássica. É também a possibilidade de investigar a matéria, a vida e a sociedade como instrumentos analíticos e teóricos comuns.

Corroborando com essa visão complexa e eco-sistêmica, Sommerman (2005) afirma que, na razão complexa, há uma determinação da forma como as dimensões desde a disciplinar até a transdisciplinar irão se revelar diante do conhecimento, visando, sobretudo, uma interação e integração diante das relações do Ser com a realidade.

Várias reflexões apontam que o surgimento das discussões em torno da complexidade, do pensamento eco-sistêmico foi concomitante ao surgimento das abordagens e sugestões metodológicas das perspectivas pluri, inter e transdisiciplinares. Perspectivas que privilegiam, sobretudo, uma abertura mais ampla, refletindo como podemos observar e interagir com a realidade de forma menos fragmentadora, mas de forma a privilegiar a realidade em suas nuances. 


\section{Educação: da disciplinaridade à transdisciplinaridade}

Contrário a essa lógica da fragmentação, da desqualificação do complexo, podemos constatar outras formas mais abrangentes de verificar a realidade, como a cultura, a visão biológica, a visão da física, da moral, da ética. Nicolescu (2000) aponta que, na metade do século XX, começa uma grande discussão a respeito da necessidade de pontes, de interligações entre as diferentes disciplinas na qual primeiro surgiu o conceito de pluri e interdisciplinaridade.

De acordo com o autor, na pluridisciplinaridade, o objeto é estudado por várias disciplinas ao mesmo tempo, mas a partir de uma única disciplina. Não deixa de ser um avanço em relação à proposta disciplinar; essa proposta pluri traz algo a mais à disciplina em questão, mas esse algo a mais ainda se inscreve na proposta disciplinar.

Nas figuras 1 e 2 abaixo, descritas por Silva apud Moraes (2008), podemos verificar as diversas possibilidades de análise e pesquisa sobre o objeto pesquisado, as diferenças ocorridas em torno da disciplinaridade e da pluridisciplinaridade.

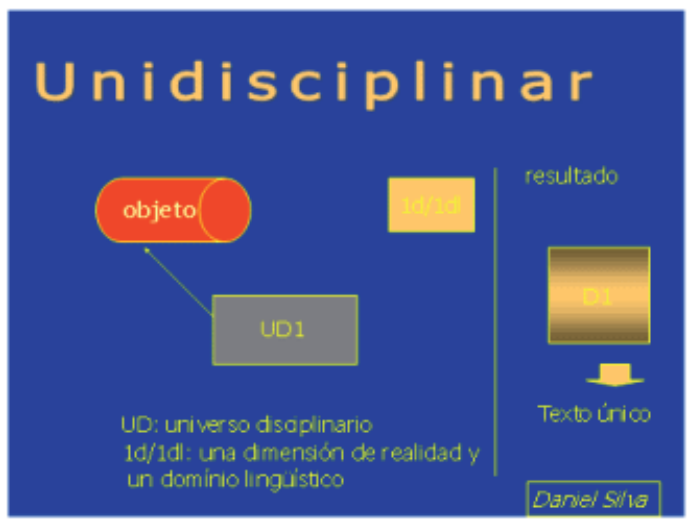

Figura 1: Dimensão Disciplinar. Fonte: Silva apud Moraes, 2008

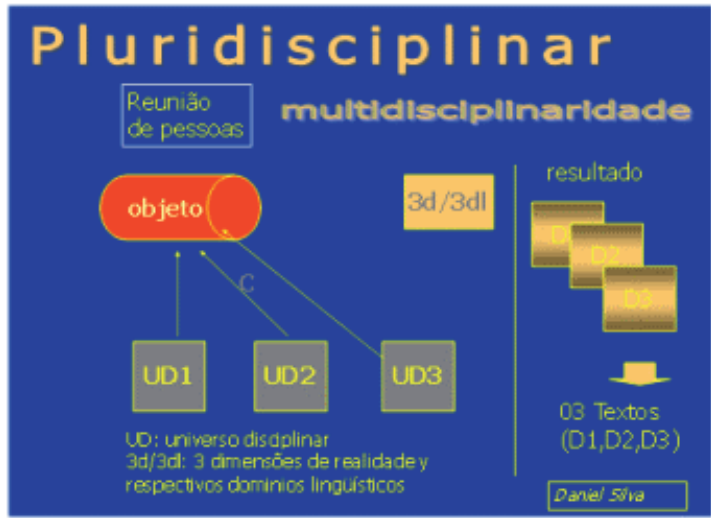

Figura 2: Dimensão Pluridisciplinar. Fonte: Silva apud Moraes, 2008

As figuras acima mostram como a disciplinaridade e a pluridisciplinaridade são estruturadas de forma compartimentada. São estruturas que analisam o objeto de forma ainda isolada, 
resultando na disciplinaridade um texto único e na pluridisciplinaridade de três textos, mas mantém o isolamento das disciplinas.

Para Nicolescu (1999), é imprescindível a existência de algo entre e através das disciplinas e além de toda e qualquer disciplina. Afirma que, do ponto de vista do pensamento clássico, não existe nada, há sim um espaço vazio, assim como sugere também o vácuo na física clássica. Contudo, diante da possibilidade dos vários níveis de realidade, o espaço entre e além das disciplinas está cheio, tal como o vácuo quântico está cheio de possibilidades. Essa é uma nova concepção que irá modificar nossa visão diante da compartimentação e trazer para ciência a reflexão sobre o pensamento complexo.

As figuras 4 e 5 abaixo demonstram que, tanto na inter como na transdisciplinaridade, há uma maior integração e interação entre as disciplinas, que a possibilidade de diálogo e busca por um resultado comum mantém a essência de cada disciplina e se torna o ponto central dessas propostas (SILVA apud MORAES, 2008).

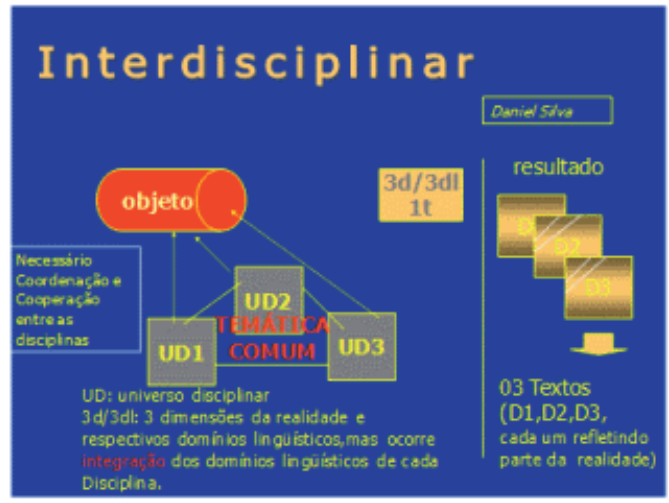

Figura 4: Dimensão Interdisciplinar. Fonte: Silva apud Moraes, 2008

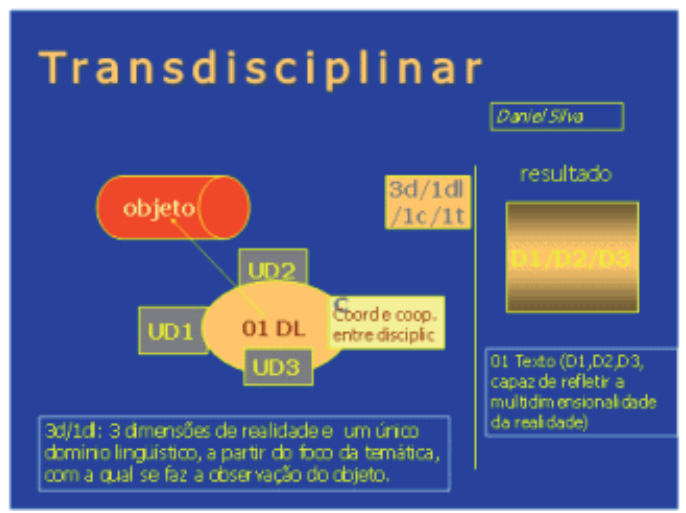

Figura 5: Dimensão Transdisciplinar. Fonte: Silva apud Moraes, 2008

Em busca de relacionar as disciplinas e trazer, de certa forma, outras possibilidades de pensar o conhecimento, a proposta transdisciplinar tem sido considerada uma dimensão preponderante no surgimento de uma nova postura diante da realidade não só pedagógica, ambiental, mas 
numa visão mais ampla do todo. É uma busca que reflete sobretudo, sobre a rica abertura para os diversos conhecimentos, para os diversos saberes.

São em torno dessas perspectivas e da complexidade que a pesquisa foi fundamentada, podendo assim verificar como as instituições pesquisadas a saber: Universidade de Brasília, Universidade Nova de Lisboa, Instituto Caliandra e Unipaz, estruturam suas atividades, isto é, quais os parâmetros que são abordados nessas instituições,

\section{Metodologia}

Utilizamos a pesquisa bibliográfica como estratégia metodológica no desenvolvimento da pesquisa para descrever autores e práticas que descrevem os fundamentos metodológicos, epistemológicos que envolvem a educação a aprendizagem como um todo, destacando autores diversos que contribuem com a reflexão em torno da temática.

A pesquisa de campo foi uma estratégia importante em nosso trabalho, pois utilizamos alguns instrumentos que complementaram a pesquisa como um todo. Nesse sentido, utilizamos a entrevista como principal instrumento metodológico de campo. No desenvolvimento do trabalho, utilizamos como instrumento a entrevista semi-estruturada e apoiamos nossa análise também em alguns documentos-referências.

\section{Resultados}

\section{Unipaz e Instituto Calliandra}

As abordagens dessas duas instituições são amparadas nas Perspectivas Eco-Sistêmica e Transdisciplinar, dando ênfase na visão complexa, relacional, não linear, difusa e mutável. As atividades dessas instituições são construídas a partir de seminários, vivências, leituras, tai-chi, biodança, contato com a natureza. Privilegiam as dimensões: física, emocional, vital, mental, psíquico-espiritual, transpessoal.

\section{Universidade de Brasília}

Foi verificado que a perspectiva transdisciplinar está em construção,não sendo ainda uma abordagem que perpassa todo o currículo da área. As abordagens além da teoria utilizam oficinas, contato com a natureza (Graduação). Estendido para pós-graduação exercícios corporais e poesias. Metodologias abertas, fundamentos teórico-epistemológicos baseados na transdisciplinaridade.

\section{Universidade de Lisboa}

Relações complexas, atuação de diversas áreas numa perspectiva pluridisciplinar. Várias ferramentas metodológicas: quali-quantitativas, entrevistas, inquéritos, relatórios, sistema de informação geográfica-SIG. Buscam o desenvolvimento de suas atividades a partir da perspectiva sistêmica, holística, visão ampla do problema. 


\section{Considerações}

Pela complexidade da temática, das diversas dimensões envolvidas, desde a disciplinaridade à transdiciplinaridade, o estudo demonstrou que não há uma exatidão no desenvolvimento dessas dimensões, mas sim uma busca de transpor a perspectiva linear que norteia o positivismo e uma tentativa de assimilação e proposição a partir das dimensões inter, pluri e transdisciplinar.

$\mathrm{O}$ estudo revelou que quase todas as instituições desenvolvem propostas que visam a transdiciplinaridade. Tanto os documentos-referência e os autores como os relatos das entrevistadas, demonstraram o desenvolvimento de várias propostas baseadas na perspectiva transdisciplinar. Contudo, é fato que tanto a transdiciplinaridade como a complexidade são propostas recentes que ainda estão num processo de assimilação, de reflexão, não só no que diz respeito aos fundamentos dessas dimensões, bem como à forma de desenvolver essas perspectivas.

Além da perspectiva transdisciplinar, também observa-se que uma das instituições trabalha na perspectiva pluridisciplinar, segundo a qual há um diálogo e uma troca de experiências entre várias disciplinas, numa abertura por uma reflexão interdisciplinar mais ampla e sistêmica.

Ficou claro que há uma intenção por parte de todas as instituições de superar o modelo tradicional de ensino, de superar o positivismo a fragmentação inerente que ainda hoje há na educação, na aprendizagem como um todo. Também que as instituições buscam uma forma de inserir outros paradigmas que essas novas concepções são um rico terreno onde a Educação poderá, pela sua complexidade inerente, inserir-se de forma mais enraizada. 


\section{Referencias}

Capra, F. A teia da vida. São Paulo: Cultrix, 1996.

Moraes, M. C. Ecologia dos saberes: complexidade, transdisciplinaridade e educação: novos fundamentos para iluminar novas práticas educacionais. São Paulo: Antakarana, 2008.

Morin, E. A ética do sujeito responsável. In: Ética, Solidariedade e Complexidade.

São Paulo: Palas Athena, 1998.

-. Ciência com consciência. Rio de Janeiro: Bertrand Brasil, 2008

-. Um novo tipo de conhecimento: transdisciplinaridade. Educação e transdisciplinaridade I. Brasília: Unesco, 2000.

—. O Manifesto da transdisciplinaridade. São Paulo: Triom, 1999.

Santos, B. S. A gramática do tempo. Para uma nova cultura política. São Paulo: Editora Cortez, 2006. Sommerman, A. Complexidade e transdisciplinaridade - centro de educação transdisciplinar -

CETRANS. In: I Encontro Brasileiro de Estudos da Complexidade 11 a 13 e julho. Curitiba: Pontifícia Universidade Católica do Paraná, 2005.

\section{Sobre la Autora}

Dra. Magda Pereira Pinto: Sou graduada em filosofía pela faculdade de filosofía e letras de Poços de Caldas. Meu mestrado realizei na Unesp de Rio Claro, onde desenvolvi a dissertação sobre a relação sociedade e natureza através da visão filosófica. No doutorado minha tese foi elaborada tendo como objetivo principal a educação e a ecologia humana, onde trouxemos a importância da visão complexa na relação sociedade e natureza. Na minha trajetória profissional trabalhei como docente da Universidade de Brasília, da Unicesp e desenvolvi diversas consultorias pelo Ministério do Meio Ambiente, Ministério da Educação e Ministério do Desenvolvimento Social entre outros, atuando na área de educação e ecologia. Atualmente sou pesquisadora do grupo ecotransd da Universidade Católica de Brasília, onde trabalho com a Profa. Dra. Maria Cândida de Moraes, com o tema transdisciplinaridade e complexidade. 